\title{
Childhood Visual Pathway Astrocytoma
}

National Cancer Institute

\section{Source}

National Cancer Institute. Childhood Visual Pathway Astrocytoma. NCI Thesaurus. Code C7534.

An astrocytoma that arises from the visual pathway and occurs during childhood. 